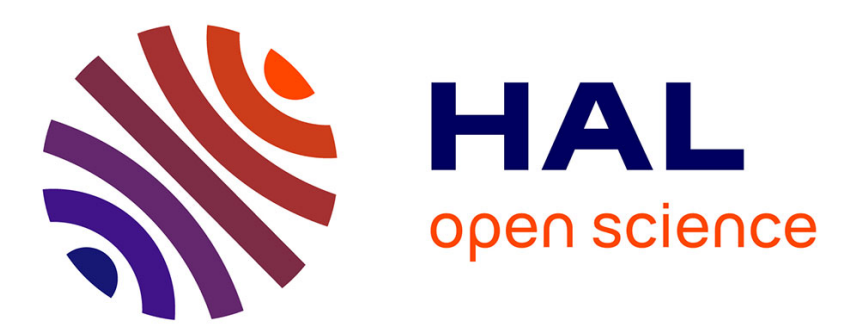

\title{
Reorientation Method to Suppress Simulator Sickness in Home Video Game Using HMD
}

\author{
Yuki Ueda, Junichi Hoshino
}

\section{To cite this version:}

Yuki Ueda, Junichi Hoshino. Reorientation Method to Suppress Simulator Sickness in Home Video Game Using HMD. 16th International Conference on Entertainment Computing (ICEC), Sep 2017, Tsukuba City, Japan. pp.370-374, 10.1007/978-3-319-66715-7_42 . hal-01771262

\section{HAL Id: hal-01771262 \\ https://hal.inria.fr/hal-01771262}

Submitted on 19 Apr 2018

HAL is a multi-disciplinary open access archive for the deposit and dissemination of scientific research documents, whether they are published or not. The documents may come from teaching and research institutions in France or abroad, or from public or private research centers.
L'archive ouverte pluridisciplinaire HAL, est destinée au dépôt et à la diffusion de documents scientifiques de niveau recherche, publiés ou non, émanant des établissements d'enseignement et de recherche français ou étrangers, des laboratoires publics ou privés. 


\title{
Reorientation Method to Suppress Simulator Sickness in Home Video Game Using HMD
}

\author{
Yuki Ueda ${ }^{1 *}$ and Junichi Hoshino ${ }^{1}$ \\ ${ }^{1}$ University of Tsukuba, Graduate school of Systems and Information Engineering, \\ 1-1-1, Tennodai, Tsukuba-shi, Ibaraki, Japan \\ ueda.yuki@entcomp.esys.tsukuba.ac.jp,jhoshino@esys.tsukuba.ac.jp
}

\begin{abstract}
While home-use HMD including Oculus Rift has been widely spread in the market today, simulator sickness mainly caused by difference between visual information and body sensation has taken up as a problem. Even though it has been proved that simulator sickness is reduced by reflecting actual physical movement to a VR space, many of approaches ever proposed had various restrictions and mechanisms easy to cause simulator sickness. In the current study, such an approach for moving within a VR space is proposed for home-use HMD that is less likely to cause simulator sickness.
\end{abstract}

Keywords: Virtual reality walking $\cdot$ Redirection $\cdot$ Simulator sickness

\section{Introduction}

With an expectation that home-use HMD including Oculus Rift is to be widely distributed in the market today, VR experience via home-use game machine and the like has become familiar to us. Image experience with a sense of immersion such as VR, however, is known to cause simulator sickness associated with symptoms including tiredness, headache, eyestrain, dizziness and nausea. Since discomfort caused by simulator sickness may turn user's long hours of VR experience into something associated with distress, it is an unavoidable bottleneck for content developers to cope with. While cause of simulator sickness is still in debate, it is believed, in particular, that difference in body sensation between reality and VR space is a major cause [1]. Approaches to make a body move within a VR space by actually moving the body were often proposed but many of them were not applied to VR experience at home because they required large experience space and extensive equipment as well. Further, in such approaches as walking back and forth within a small walking area such as Redirected Walking [2] and Reorientation Technique [3], there was a problem that the mechanism to correct direction when reached at the end of the walking area caused some restrictions to contents. In the current study, a sequential move approach within VR space is proposed which is less likely to cause simulator sickness without restricting experience environment and contents.

\section{System Overview}

With a purpose to achieve visually sequential horizontal movement without any restriction for experience environment and contents while inhibiting simulator sickness, the system has defined the requirements as follows: 
(1) Not to require extensive equipment;

(2) To be able to realize within a small experience space;

(3) Not to restrict contents;

(4) To make users actually walk within the VR space to transfer; and

(5) Not to generate difference in rotation angle during direction correction.

In order to meet the requirements above, we have determined to take an approach to give a sensation of continuous walk in a large VR space by walking back and force in a small walking area. Even though restrictions for routes and visual presentation of rotation angle different from reality has been adopted in order to prevent users from recognizing direction correction in previous studies on Redirected Walking [2] and Reorientation Technique [3], reduction of simulator sickness is tried in the system by intentionally make users notice that they are correcting direction.

By the system consisting of a PC for VR environment drawing, HTC vive as a home-use HMD capable of position estimation, base station and controller for exclusive use of HTC vive and a flat floor for walking, users are able to arbitrarily shift between the following two conditions by operating the controller:

[Movement phase]

Users are able to freely walk within the walking area. Since it is impossible to take a step further when reaching the end of the walking area, it is required to correct the direction by shifting to rotation phase. Besides, the walking area ground was colored by different color from that of surrounding ground in order for users to be able to recognize the walking area.

[Rotation phase]

Users rotate on the spot. As foreground is rotated in synchronization with user rotation, the foreground of the users remains fixed in their eyesight. In this case, it is possible to present an eyesight without any difference in rotation angle to users by displaying independent visual background [4] fixed at global coordinate system making it further possible to give users a sensation that the foreground is rotating along with the body's rotation. Recommended rotating direction and angle guide is displayed for users as shown in Fig.2.

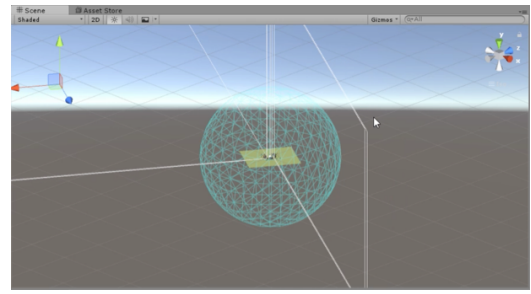

Fig. 1. Independent visual background

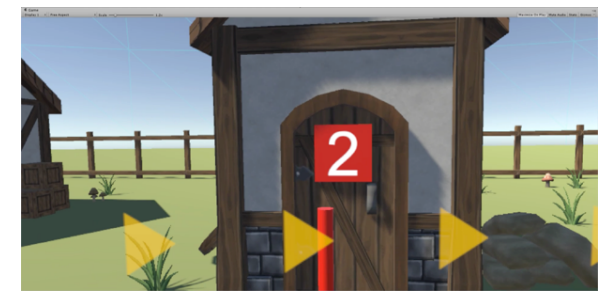

Fig. 2. Rotating direction recommendation guide

\section{Experiments}

In the current experiment cooperated by 8 persons in their 20's (male: 7, female: 1 ), a task was imposed to them in which they walk around through five check points set up in the VR space to move a route equivalent of about $45 \mathrm{~m}$ of distance both by a proposed approach 
preparing a walking area with a size of $2.0 \mathrm{~m} \times 1.5 \mathrm{~m}$ and a movement approach based on a home-use game operation using a normal keyboard/mouse. Overview of VR environment and position of each check point is shown in Fig. 3 and Fig. 4, respectively. The two types of movement approaches were compared by time required for subjects to walk through all of the check points as well as evaluation value of SSQ [5] performed immediately after experiment completion and contents of hearing.

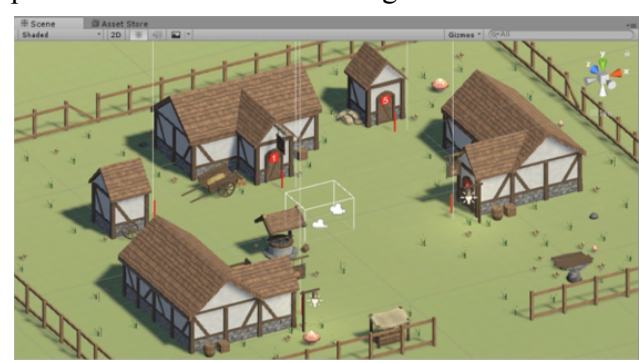

Fig. 3. Overview of VR environment

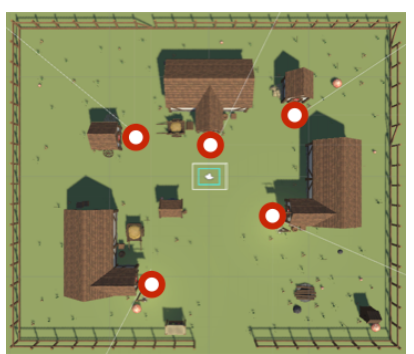

Fig. 4. Positions of check points

Table 1 below shows mean time required for subject to have completed the task and standard deviation. It has been proved that the proposed system requires much longer time compared with a movement approach by keyboard/mouse.

Table 1 : Comparison of required time

\begin{tabular}{|c|c|c|c|c|}
\hline & \multicolumn{2}{|c|}{ Keyboard/Mouse } & \multicolumn{2}{|c|}{ The proposed system } \\
\hline & Mean & $S D$ & Mean & $S D$ \\
\hline Time & $46 \mathrm{sec}$ & $8 \mathrm{sec}$ & $208 \mathrm{sec}$ & $54 \mathrm{sec}$ \\
\hline
\end{tabular}

In addition, evaluation values were obtained by SSQ for SSQ (Total Score) as a comprehensive index for motion sickness, SSQ-N (Nausea), SSQ-O (Oculomotor) and SSQ-D (Disorientation). The result is shown in Table 2. The tougher is the symptom, the higher is the evaluation value. As a result of Mann-Whitney $U$ test for each evaluation value, it has been proved that the proposed system shows significant difference in evaluation values of SSQ-TS $(\mathrm{Z}=2.013, \mathrm{p}<0.05)$ and SSQ-O $(\mathrm{Z}=2.016, \mathrm{p}<0.05)$ compared with those of the movement approach based on keyboard/mouse.

Table 2 : Comparison of SSQ results

\begin{tabular}{|c|c|c|c|c|}
\hline & \multicolumn{2}{|c|}{ Keyboard/Mouse } & \multicolumn{2}{|c|}{ The proposed system } \\
\hline & Mean & $S D$ & Mean & $S D$ \\
\hline SSQ-TS* & 38.80 & 23.28 & 20.57 & 15.19 \\
\hline SSQ-N & 27.42 & 19.34 & 10.73 & 12.10 \\
\hline SSQ-O* & 50.22 & 28.35 & 23.69 & 17.13 \\
\hline SSQ-D & 59.16 & 53.35 & 36.54 & 40.55 \\
\hline
\end{tabular}




\section{Conclusion}

It has been also revealed from the experiment that the proposed system is superior to the movement approach based on keyboard/mouse in degree of comprehensive motion sickness as expressed by SSQ-TS and degree of eye fatigue as expressed by SSQ-O in case of moving the same route. In the hearing after the experiment, such opinions were obtained that it was impossible for them to follow the movement on the screen by the movement approach based on keyboard/mouse even if operating on their own or that they got tired due to unintended movement. In contrast, there was an opinion for the proposed system that the system is intuitive causing less fatigue because images always moved in synchronization with their own movement. From the experiment results and opinions for it, it is believed that simulator sickness has been relieved in the proposed system by reducing difference in body sensation between the reality and VR space. For the proposed system, however, there was a complaint of feeling sick due to frequent correction of direction. It is understood as caused by the fact that many times of direction correction is required in order to move long distance because of the small walking area in reality. In addition, it is also believed that required time was greatly prolonged for the proposed system due to the frequent direction correction compared with movement approach based on keyboard/mouse. Resolution for the problem may include increase of moving speed within a range that users do not feel difference in the body sensation in addition to expansion of walking area in reality.

Since it took much more time by the system compared with the movement approach based on keyboard/mouse in the current experiment conducted in such a way to move along the same route, we thought it necessary to conduct also such experiments by the same movement speed and experiencing time as well. It is believed because the faster is the movement speed within a VR space the larger is the difference in the body sensation from the reality causing intense simulator sickness and longer time of experience may cause deterioration of simulator sickness. As we also felt a necessity to improve usability aiming at shortening a period of time until getting familiar with the system as well as method of displaying rotating direction not to cause cables to wind around the body in addition to opinions obtained, we would like to work on these challenges in the future.

\section{References}

[1] LaViola Jr, J. 2000. A discussion of cybersickness in virtual environments. ACM SIGCHI Bulletin, 32(1):47-56.

[2] Razzaque, S., Kohn, Z., Whitton, M. 2001. Redirected Walking. EuroGraphics 2001.

[3] Peck, T., Whitton, M., Fuchs, H. 2008. Evaluation of Reorientation Techniques for Walking in Large Virtual Environments. Virtual Reality Conference, 2008. VR '08. IEEE. [4] Prothero, J.D., Draper, M.H., Furness, T.A., Parker, D.E., Wells, M.J. 1999. The use of an independent visual background to reduce simulator side-effects. Aviation, Space, and Environmental Medicine, 70(3):135-187.

[5] Kennedy R. S., Lane, N. E., Lilienthal, M. G. 1993. Simulator sickness questionnaire: An enhanced method for quantifying simulator sickness. The International Journal of Aviation Psychology, 3(3):203-220. 